\title{
贲Fermilab
}

MEMORANDUM OF UNDERSTANDING

FOR THE 2011 - 2012 NEUTRINO PROGRAM

T-1013

NOvA Near Detector On the Surface (NDOS)

February 16, 2011

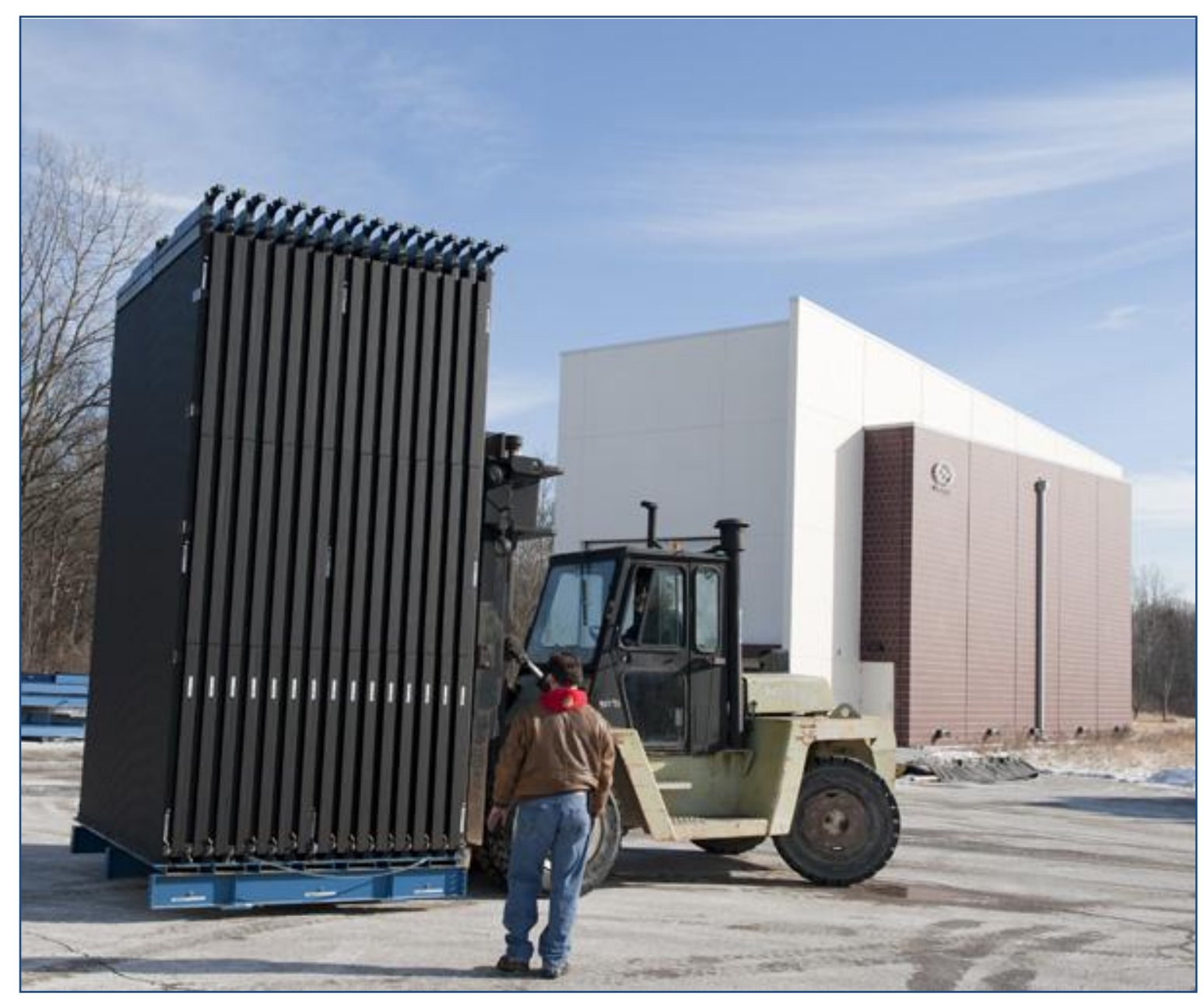


MOU for T-1013: NDOS

\section{TABLE OF CONTENTS}

$\begin{array}{ll}\text { INTRODUCTION } & 3\end{array}$

I. Personnel And Institutions $\quad \mathrm{X}$

II. EXPERIMENTAL AREA, BEAMS AND SCHEDULE CONSIDERATIONS X X

III. ReSPONSIBILITIES By INSTITUTION - NON FERMILAB $\quad \mathrm{X}$

IV. RESPONSIBILITIES By INSTITUTION - FERMILAB $\quad$ X

4.1 Fermilab ACCELERAtor Division X X

4.2 Fermilab Particle Physics Division $\quad$ X

4.3 Fermilab Computing Division $\quad$ X

4.4 FeRmiLAB ES\&H SeCtion $\quad \mathrm{X}$

V. SUMMARY OF COSTS X X

VI. SPECIAL CONSIDERATIONS X X

$\begin{array}{ll}\text { SIGNATURES } & 12\end{array}$

APPENDIX I - HAZARD IDENTIFICATION CHECKLIST 13 


\section{INTRODUCTION}

This is a memorandum of understanding between the Fermi National Accelerator Laboratory (Fermilab) and the experimenters of [collaboration institutions] who have committed to participate in beam tests to be carried out during the 2011 - 2012 Fermilab Neutrino program.

The memorandum is intended solely for the purpose of recording expectations for budget estimates and work allocations for Fermilab, the funding agencies and the participating institutions. It reflects an arrangement that currently is satisfactory to the parties; however, it is recognized and anticipated that changing circumstances of the evolving research program will necessitate revisions. The parties agree to modify this memorandum to reflect such required adjustments. Actual contractual obligations will be set forth in separate documents.

Description of Detector and Tests:

[Description of experiment, see examples. Inclusion of pictures or diagrams is highly recommended.] 


\section{MOU for T-1013: NDOS}

\section{Personnel AND InSTITUTIONS:}

Spokespersons and Physicists in charge of Beam Tests: Gary Feldman, Mark Messier

Fermilab liaison: Peter Lucas, Sam Childress

The group members at present are:

\begin{tabular}{|l|l|l|l|l|}
\hline & Institution & Collaborator & Rank/Position & Other Commitments \\
\hline \multirow{4}{*}{1.1} & \multirow{4}{*}{$\begin{array}{l}\text { University of Texas at } \\
\text { Arlington }\end{array}$} & John Doe & Associate Professor & ATLAS, ILC \\
\cline { 3 - 5 } & & Andrew Jackson & Professor & D $\varnothing$, ATLAS, ILC \\
\cline { 3 - 5 } & & Steven Weinberg & Senior Researcher & ATLAS, ILC \\
\cline { 3 - 5 } & George Bush & Visiting Researcher & ILC \\
\cline { 3 - 5 } & Edwin McMillan & Undergraduate & ILC \\
\hline 1.2 & Stanford University & Steven Chu & Professor & DOE \\
\hline 1.3 & CERN & Robert Aymar & Director General & LHC \\
\hline
\end{tabular}




\section{EXPERIMENTAL AREa, BeAmS AND SCHEdUle Considerations:}

\subsection{LOCATION}

2.1.1 The apparatus for the beam test(s) will be located in the NOvA Detector Surfave Building.

2.1.2 Experimenters will monitor the detector and beam from the Nu Control Room, in Wilson Hall 12-NW.

\section{2 $\underline{\text { BEAM }}$}

\subsubsection{BEAM TYPES AND INTENSITIES}

Particles: Neutrinos (vs anti-neutrinos?)

Intensity: 10k - 100k in units of particles/ 4 sec spill

Beam spot size: about $10 \mathrm{~cm}^{2}$

\section{[Specify other details if needed.]}

\subsubsection{BEAM SHARING}

The experiment will run parasitically with the MINOS, MINERvA, and Mini BooNE experiments currently using the NuMI and BooNE beams, respectively.

\subsubsection{RUNNING TIME}

The experiment intends to operate the detector 24 hours a day, 7 days a week, as the beam is available, until the beam is shut off at the beginning of the 2012 shutdown.

\subsection{EXPERIMENTAL CONDITIONS}

\subsubsection{AREA INFRASTRUCTURE}

\subsubsection{ELECTRONICS NEEDS}

The experiment is currently not using any PREP equiptment, but may choose to make a request for some small things in the future. 


\section{MOU for T-1013: NDOS}

\subsubsection{DESCRIPTION OF TESTS}

[Describe the day to day activities of conducting the experiment, and any special needs the experiment might have. When would you change detectors, beam types, etc. ]

\subsection{SCHEDULE}

The experiment will run until beam is shut off at the start of the 2012 Fermilab shutdown. 


\section{MOU for T-1013: NDOS}

\section{RESPONSIBILITIES BY INSTITUTION - NON FERMILAB}

3.1 NAME OF InSTITUTION:

[List or describe contributions to the experiment by this institution. Include a cost estimate.] 


\section{RESPONSIBILITIES BY INSTITUTION - FERMILAB}

\subsection{FERMILAB ACCELERATOR DIVISION:}

4.1.1 Use of Booster and NuMI neutrino beams as outlined in Section II.

4.1.2 Maintenance of all existing standard beam line elements (SWICs, loss monitors, etc) instrumentation, controls, clock distribution, and power supplies.

4.1.3 Scalers and beam counter signals should be made available in the control room

4.1.4 Connection to beams control console and remote logging (ACNET) should be made available.

4.1.5 Position and focus of the beam on the experimental devices under test will be under control of MCR.

4.1.6 Coordination of overall beam activities for the NuMI and BooNE beams.

\subsection{FERMILAB PARTICLE PHYSICS DIVISION:}

4.2.1 The test-beam efforts in this MOU will make use of Booster and NuMI neutrino beams as outlined in Section II. The Fermilab Particle Physics Division will be responsible for coordinating overall activities in the MINOS Underground Area. [0.4 person-weeks]

4.2.2 Technical support to assist in installing the detector.

\subsection{FERMILAB COMPUTING DIVISION}

4.3.1 Internet access should be continuously available in the control room.

\subsection{FERMILAB ES\&H SECTION}

\subsubsection{Assistance with safety reviews.}

4.4.2 Provide necessary training for experimenters. 
MOU for T-1013: NDOS

V. Summary OF COSTS

\begin{tabular}{|c|c|c|}
\hline Source of Funds [\$K] & Materials \& Services & $\begin{array}{c}\text { Labor } \\
\text { (person-weeks) }\end{array}$ \\
\hline Particle Physics Division & 0.0 & 1.0 \\
\hline Accelerator Division & 0 & 0.5 \\
\hline Computing Division & 0 & 0 \\
\hline & & 1.5 \\
\hline Totals Fermilab & $\$ 0.0 \mathrm{~K}$ & [specify] \\
\hline Totals Non-Fermilab & [specify from Section III] & \\
\hline
\end{tabular}




\section{MOU for T-1013: NDOS}

\section{SPECIAL CONSIDERATIONS}

6.1 The responsibilities of the Spokespersons and the procedures to be followed by experimenters are found in the Fermilab publication "Procedures for Researchers": (http://www.fnal.gov/directorate/PFX/PFX.pdf). The Spokespersons agree to those responsibilities and to follow the described procedures.

6.2 To carry out the experiment a number of Environmental, Safety and Health (ES\&H) reviews are necessary. This includes creating an Operational Readiness Clearance document in conjunction with the standing Particle Physics Division committee. The Spokespersons will follow those procedures in a timely manner, as well as any other requirements put forth by the Division's Safety Officer.

6.3 The spokespersons will ensure at least one person is present in the $\mathrm{Nu}$ Control Room whenever the detector is being operated and that this person is knowledgeable about the experiment's hazards.

6.4 All regulations concerning radioactive sources will be followed. No radioactive sources will be carried onto the site or moved without the approval of the Fermilab ES\&H section.

6.5 All items in the Fermilab Policy on Computing will be followed by the experimenters. (http://computing.fnal.gov/cd/policy/cpolicy.pdf).

6.6 The Spokespersons will undertake to ensure no PREP or computing equipment be transferred from the experiment to another use except with the approval of and through the mechanism provided by the Computing Division management. The Spokespersons also undertake to ensure no modifications of PREP equipment take place without the knowledge and written consent of the Computing Division management.

6.7 The experimenters will be responsible for maintaining both the electronics and the computing hardware supplied by them for the experiment. Fermilab will be responsible for repair and maintenance of the Fermilab-supplied electronics. Any items for which the experiment requests that Fermilab performs maintenance and repair should appear explicitly in this agreement.

At the completion of the experiment:

6.8 The Spokespersons are responsible for the return of all PREP equipment, computing equipment and non-PREP data acquisition electronics. If the return is not completed after a period of one year after the end of running the Spokespersons will be required to furnish, in writing, an explanation for any non-return.

6.9 The experimenters agree to remove their experimental equipment as the Laboratory requests them to. They agree to remove it expeditiously and in compliance with all ES\&H requirements, including those related to transportation. All the expenses and personnel for the removal will be borne by the experimenters unless removal requires facilities and personnel not able to be supplied by them, such a rigging, crane operation, etc.

6.10 The experimenters will assist the Fermilab Divisions and Sections with the disposition of any articles left in the offices they occupied.

6.11 An experimenter will be available to report on the test beam effort at a Fermilab All Experimenters' Meeting. 


\section{SigNATURES:}

/ / 2011

Gary Feldman, Experiment Spokesperson

/ / 2011

Mark Messier, Experiment Spokesperson

/ / 2011

Michael Lindgren, Particle Physics Division, Fermilab

/ / 2011

Roger Dixon, Accelerator Division, Fermilab

/ / 2011

Peter Cooper, Computing Division, Fermilab

/ / 2011

Nancy Grossman, ES\&H Section, Fermilab

/ /2011

Greg Bock, Associate Director for Research, Fermilab

Stuart Henderson, Associate Director for Accelerators, Fermilab 


\section{APPENDiX I: - HAZARD IdENTIFICATION CHECKLIST}

Items for which there is anticipated need should be checked.

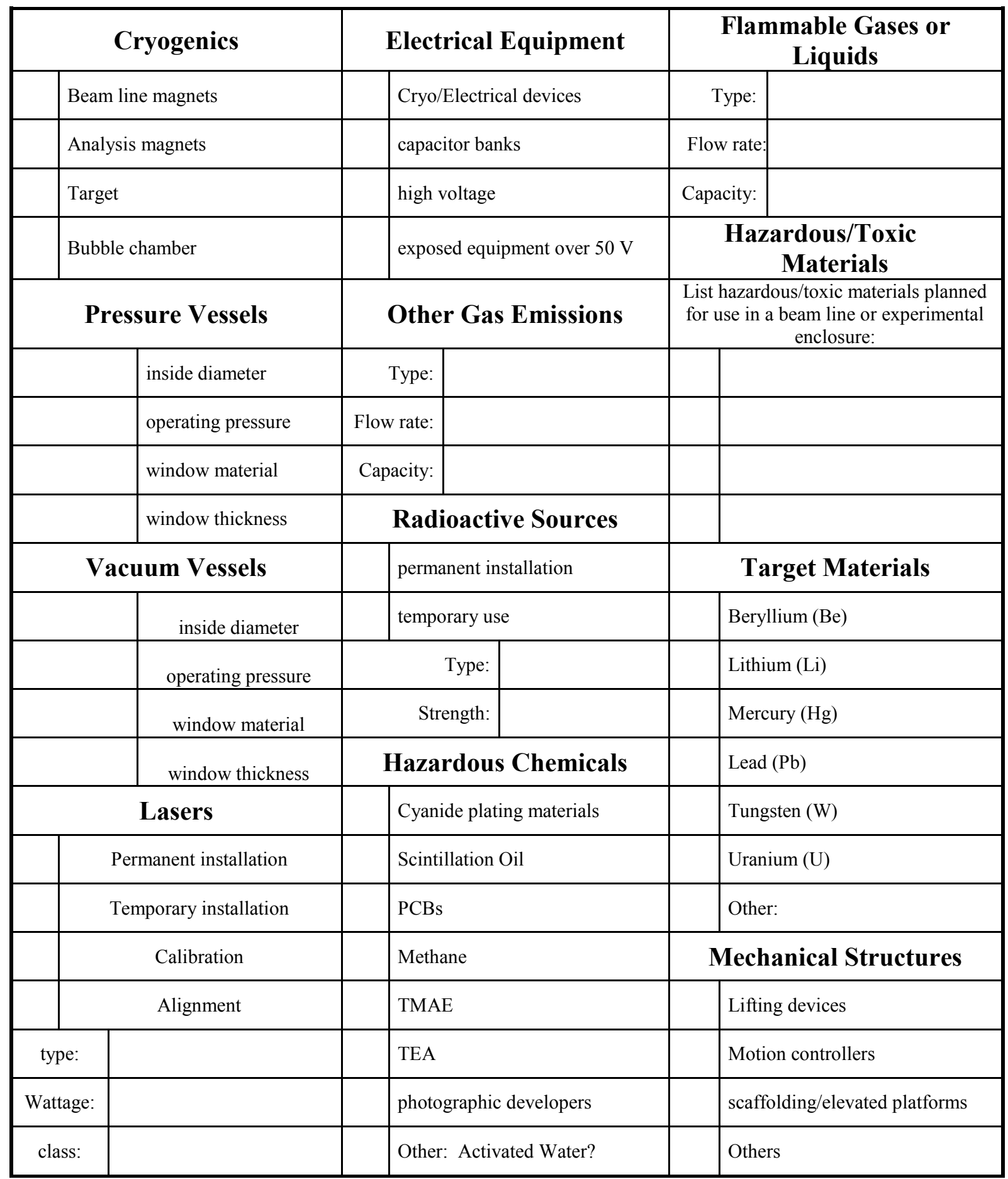

